\title{
DEVELOP THE HYSTERESIS MODEL OF CONCRETE BASED ON FIBER ELE- MENT IN ABAQUS
}

\author{
QI Yong-le ${ }^{1}$, HAN Xiao-lei ${ }^{2}$, Ji Jing ${ }^{2}$ \\ ${ }^{1}$ College of Civil Engineering and Transportation, South China University of Technology \\ (q.yongle@mail.scut.edu.cn) \\ ${ }^{2}$ State Key Laboratory of Subtropical Building Science, South China University of Technol- \\ ogy
}

\begin{abstract}
Due to the complicated material behavior during the earthquake, the precision of simulation mainly depends on the hysteresis model of concrete and reinforcement. ABAQUS has strong nonlinear analysis ability, but its damaged-plastic model for concrete does not support spatial beam element. Therefore, the uniaxial hysteresis model suitable for fiber model of concrete was developed by using the interface UMAT in this paper. The fiber beam model is suitable for global elastic-plastic analysis of frame which is subjected to the combined action of cyclic lateral and gravity loads. The model is verified by experiments and the results show that the fiber model developed by authors possesses better accuracy and time-saving compared with traditional finite element model using solid element. It can be used with high calculation efficiency to analyze frames subjected to cyclic loading due to earthquake.
\end{abstract}

Keywords: Fiber model, Concrete column, Hysteretic relation, UMAT

\section{INTRODUCTION}

Being the primary members in concrete frame structures, reinforced concrete (RC) present the significant inelastic features under the earthquakes ${ }^{[1]}$. Repeated number of large amplitude cycles may lead to degradation in lateral strength and stiffness. Accurate prediction of the mechanical properties and the residual deformation of RC columns under earthquakes are important to assess the damage degree of the structure. The current element models simulating the RC beam-columns include the three-dimensional solid finite element model and the discrete rod element model. Although the three-dimensional solid finite element model can accurately simulate some important nonlinear behaviors of the components, the development of this model is limited greatly by the high computational cost due to the large number of nodes and elements. In contrast, the distributed plastic hinge model can simulate the performance of components from the macro view and can also provide deep insight into local nonlinear behaviors. The model is simple and time-saving, which wins favor among researchers ${ }^{[2 \sim 4]}$. Fiber beam model based on rod-system structure mechanics and uniaxial material model 
is one of the distributed plastic hinge model. Fiber beam model has high solution efficiency and accuracy when used for predicting the response of whole concrete structures under earthquake $^{[5 \sim 6]}$.

A hysteretic constitutive model suitable for fiber beam element is needed when simulating the response of $\mathrm{RC}$ frame under earthquakes. Concrete smeared cracking model, cracking model for concrete and concrete damaged plasticity model are the only three concrete constitutive models provided by ABAQUS ${ }^{[7]}$. All are unable to meet this requirement. However, ABAQUS provides interface so that an appropriate uniaxial concrete hysteretic constitutive model can be added into ABAQUS to simulate the mechanic behaviors of the concrete beam-column components under earthquakes.

\section{CONSTITUTIVE RELATION OF MATERIAL}

\subsection{The modified Kent-Park concrete constitutive relation}

The modified Kent-Park concrete constitutive ${ }^{[8]}$ is a commonly used uniaxial constitutive relation. The skeleton curve is modified by Park and Priestley in considering the confined effect of stirrups to increase the strength and ductility of concrete. The hysteresis law is proposed by Karsan and Jirsa ${ }^{[9]}$, which is based on the RC hysteresis performance experiment data of Sinha ${ }^{[10]}$. The concrete damage is considered by the degradation of the slope of unloading segment.

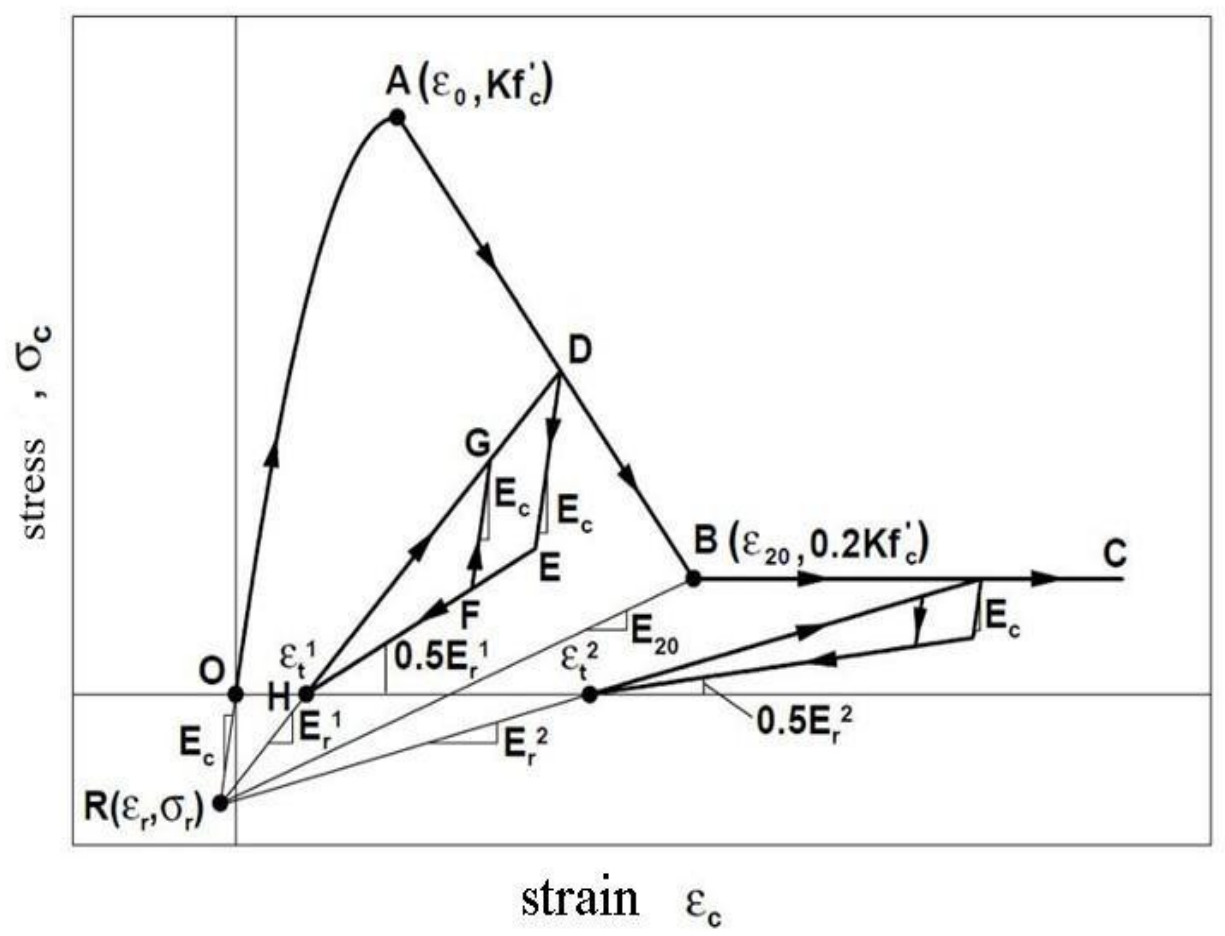

Figure 1 Stress-strain relation of concrete

The modified Kent-Park Constitutive curve is shown in Figure 1 .The compression zone is divided into three sections, namely, ascending, descending and horizontal segment. The formula of the model is simple and the numerical method is stable, which could also re- 
flects the stiffness degradation under cyclic loading and hysteretic energy assuming characteristics. Also, the model can better reflect the actual mechanical behaviors of concrete that has been widely used in the macro-element program such as OpenSEES.

\subsection{The constitutive relation of steel}

Reinforcement usually uses bilinear perfect elastic-plastic constitutive relation; however, it cannot well describe the Bauschinger effect. Therefore, this paper adopts the reinforcement constitutive of the reference, which incorporates the Bauschinger effect for cyclic loading based on the literature [11], as shown in Figure 2. The detailed meaning of the parameters can be found in the literature [11].

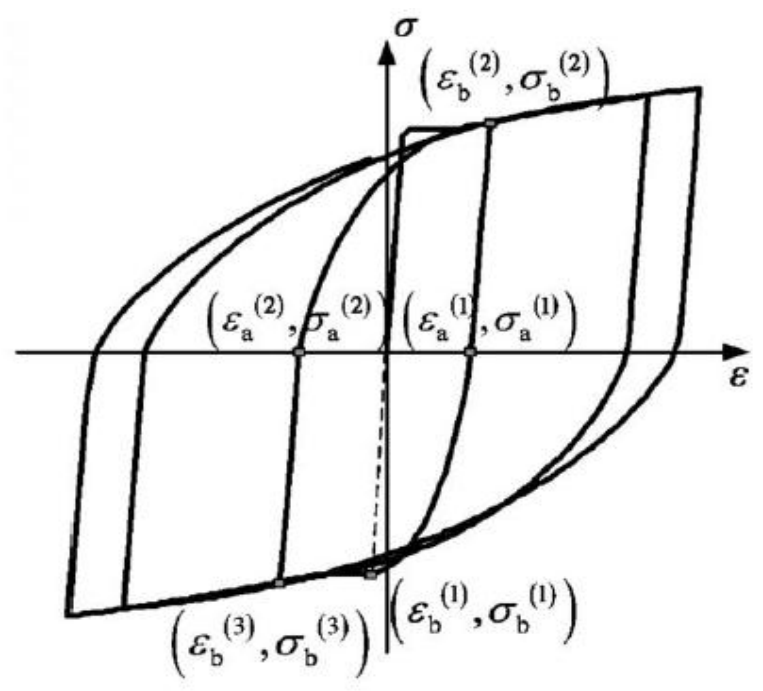

Figure 2 Stress - strain relation of steel

\section{THE CHOOSE OF THE ELEMENT}

The fiber element, as is shown in Figure 3, the section of which is divided into a number of fibers. Each fiber is uniaxial loaded and the uniaxial stress-strain relation is used to describe the mechanical behaviors of fiber materials. In spatial analysis, there are 2 nodes linear beam B31, 3 nodes quadratic beam B32 and 2 nodes cubic beam B33, of which the first two are Timoshenko beams and the last one is the Euler beam. In the simulation of large-scale projects, if the element numbers of beam-column divided are small, B31 using a linear interpolation function will significantly increase the stiffness of the structure, thus changing the dynamic characteristics of the structure. It is recommended to use quadratic Timoshenko beam elements B32, which has a good convergence performance. 


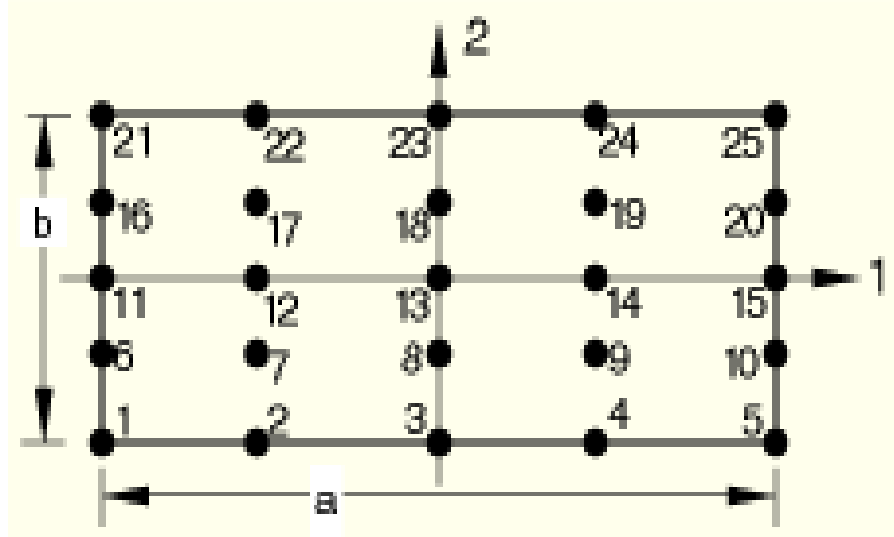

Figure 3 Integral points of beam element

In ABAQUS, the cross-section of spatial rectangular beam element B32 has 25 integral points, as shown in Figure 3. The mechanical behavior of cross-section is integrated by the behavior of these points. By using UMAT, the new added integration points can be assigned with different material properties, which provide great flexibility when defining the section, especially in adding the steel rebar.

\section{THE FLOW CHART OF THE USER SUBROUTINES}

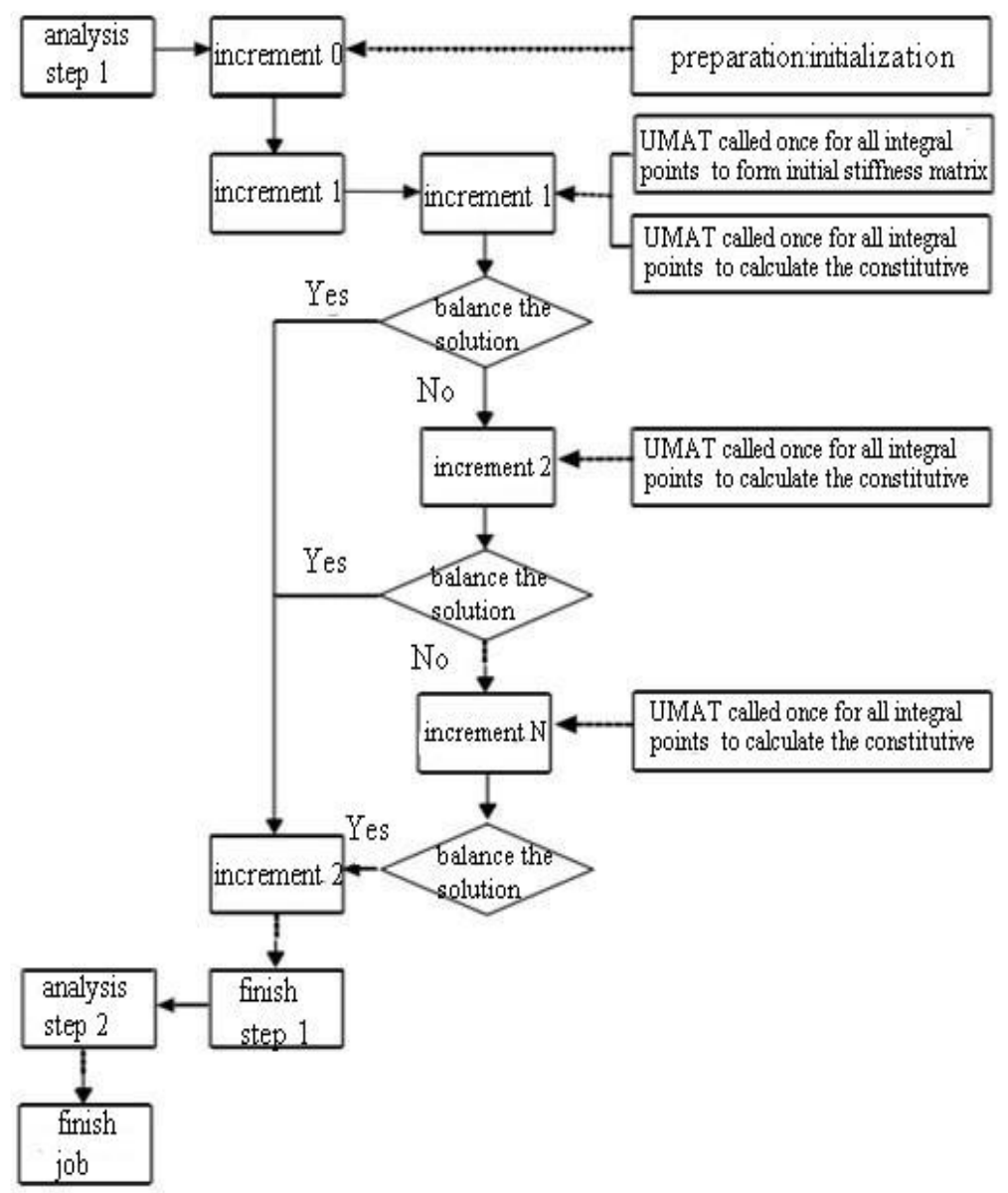

Figure 4 the flow chart of calling UMAT in ABAQUS 
The constitutive library provided in ABAQUS contains a range of linear and nonlinear material models for all of these categories of materials. In general the library has been developed to provide those models that are most usually required for practical applications. There are several distinct models in the library; and for the more commonly encountered materials (metals, in particular), several ways of modeling the material are provided, each suitable to a particular type of analysis application. But the library is far from comprehensive: the range of physical material behavior is far too broad for this ever to be possible. The analyst must review the material definitions provided in ABAQUS in the context of each particular application. If there is no model in the library that is useful for a particular case, ABAQUS/Standard contains a user subroutine-UMAT. In these routines the user can code a material model (or call other routines that perform that task). This "user subroutine" capability is a powerful resource for the sophisticated analyst who is able to cope with the demands of programming a complex material model ${ }^{[7]}$. Figure 4 briefly illustrates the increment in UMAT calculation

\section{TEST VERIFICATION}

\subsection{Compare with experiment data}

In order to verify the precision of the fiber model, a simulation is carried out. The cross section of the column is $250 \mathrm{~mm} \times 250 \mathrm{~mm}$. Concrete strength is $37.6 \mathrm{MPa}$. Transverse steel yield stress is $485 \mathrm{MPa}$, and strength is $606.1 \mathrm{Mpa}$. Detail of the specimen is in Reference [12].

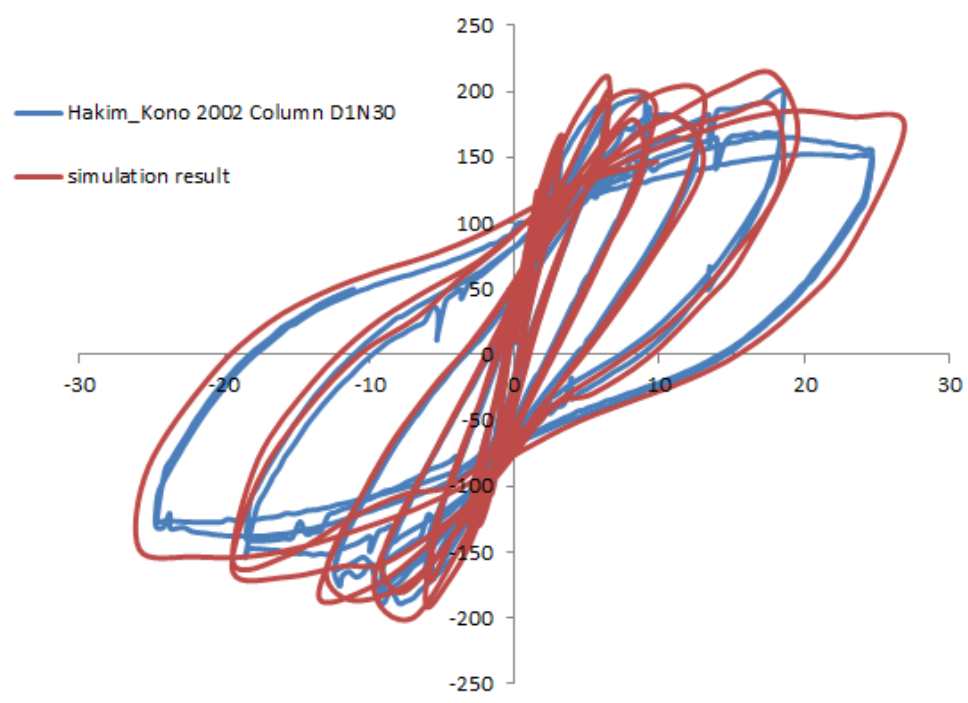

Figure 5 The simulating result of this paper

The element is divided into ten parts along the length of the column. Figure 5 show that the ultimate strength and peak strain of both are similar. Concrete constitutive of this paper has high precision. 


\subsection{Compare with solid finite element method}

The test specimen 3D4 was designed for pure flexure failure. Detail of the specimen is in References [13]. The column specimens conform to the modern code standards for seismic design. They were constructed with $25 \mathrm{MPa}$ concrete, deformed bars, and transverse reinforcement with 135 degree hooks. The lateral force-lateral drift envelope of the column structures is shown in Figure 6. The comparison of numerical simulation of RC column test in literature with the results in this paper shows consistency, indicating that the constitutive models of the materials and its analysis method used in this paper can fully and accurately reflect complex mechanic behaviors of the RC columns under earthquakes. But the time cost of the fiber element is significant smaller than the traditional finite element models using 3D solid element.

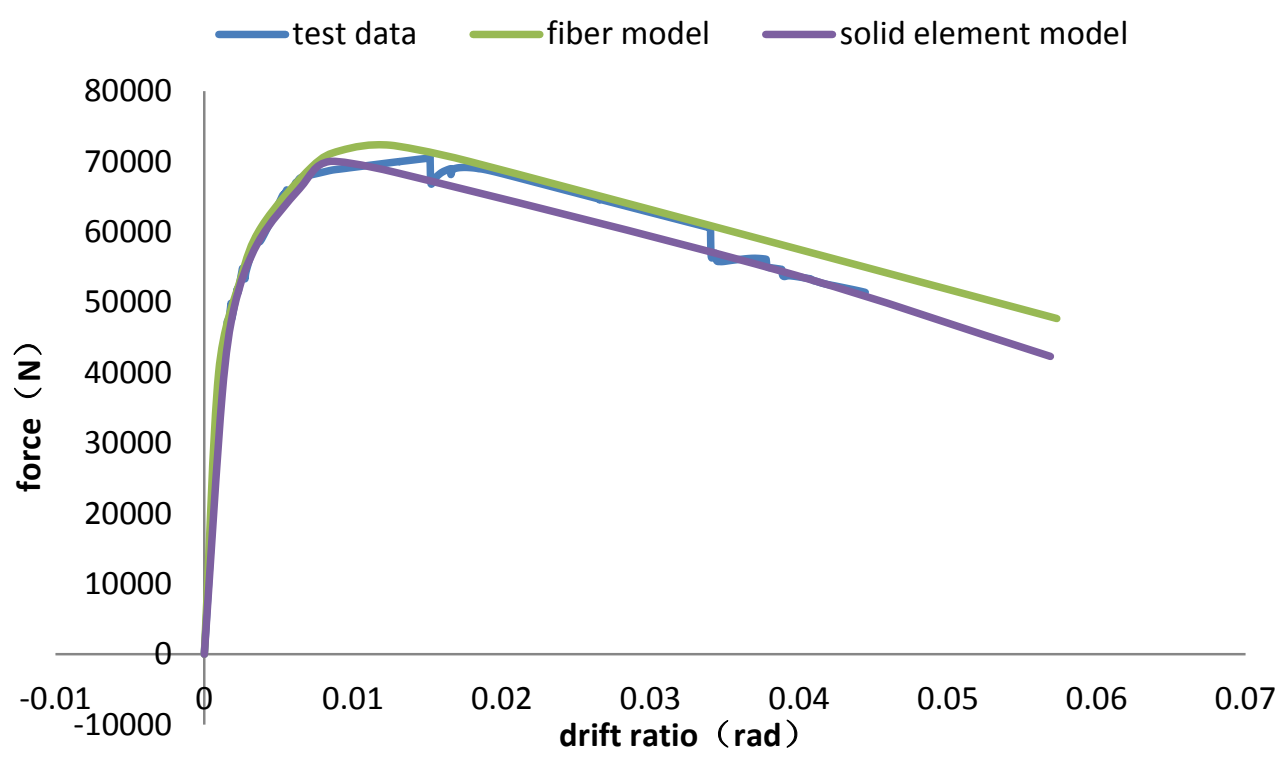

Figure 6 Comparison between simulation and test result

\section{CONCLUSION}

(1) Based on UMAT and B32 beam element provided by ABAQUS, a hysteresis model is developed to solve the technical problems when using ABAQUS for the elastic-plastic analysis of the structure. The fiber beam model possesses high solution efficiency and simple modeling procedures compared to the traditional finite element models.

(2) Elastic-plastic fiber model reflect the stiffness and resilience features from the stress-strain relationship, which can ensure the accuracy of the results. It can avoid the error when using other simplified models. The prediction results compared to the static and quasi static experimental data of column members have showed that the fiber beam model has widely applicability and high precision. 


\section{REFERENCES}

[1] Ye Lieping, Zhao Zuozhou. "Concrete structures (Edition 2, Volume 2)" [M]. Beijing: Tsinghua University Press, 2006. (in Chinese)

[2] Jiang Jianjing, He Fanglong, He Yibin, Lu Xinzheng. "Finite element analysis and applications" $[\mathrm{M}]$. Beijing: China mechine press, 2006

[3] C E Zhou, and F J Vecchio. "Nonlinear Finite Element Analysis of Reinforced Concrete Structures Subjected to Transient Thermal Loads"[J]. Computers and Concrete. 2005, 2(6):455-479.

[4] Lu Xinzheng, Miao Zhiwei, Huang Yuli, Ye Lieping. "Simulation for the collapse of concrete tall building under static and dynamic load" [A]. MSC. Software 2005 annual symposium of users in China [C]. Chengdu: 2005. 1-10. (in Chinese)

[5] Jiang Jianjing, Lu Xinzheng, Ye Lieping. "Finite element analysis of concrete structures"[M]. Beijing: Tsinghua University Press, 2005. (in Chinese)

[6] Neuenhofer A, and Filippou F C. "Evaluation of nonlinear frame finite-element models"[J]. Journal of Structural Engineering, 1997, 123(7): 958-966.

[7] ABAQUS Version 6.8 User and Theory Manual [Z]. Habbitt, Karlsson and Sorensen Inc, USA, 2009.

[8] Kent D C. “Inelastic Behavior of Reinforced Concrete Members with Cyclic Loading”[D]. University of Canterbury, Christchurch, New Zealand, 1969.

[9] Karsan I D, and J O Jirsa. "Behavior of concrete under compressive loadings"'J]. ASCE Journal of the Structural Division, 1969, 95(12):2543-2563.

[10] Sinha B P, K H Gerstle, and L G Tulin. "Stress-strain relations for concrete under cyclic loading"'[J]. Journal of the American Concrete Institute, 1964, 61(2):195-211.

[11] Légeron F, Paultre P, Mazar J. "Damage mechanics modeling of nonlinear seismic behavior of concrete structures"[J]. Struct Eng, 2005, 131(6): 946-954.

[12] Kono, Susumu, Watanabe, Fumio, "Damage Evaluation of Reinforced Concrete Columns Under Multiaxial Cyclic Loadings"[R]. The Second U.S.-Japan Workshop on Performance-Based Earthquake Engineering Methodology for Reinfoced Concrete Building Structures.

[13] Bora Acun, Halûk Sucuoğlu. "Performance limits for reinforced concrete columns under severe displacement cycles”[C]. 3rd fib International Congress: 2010. 1-12. 